\title{
CRISTALLISING A CONCEPT: A BIBLIOMETRIC ANALYSIS OF CORPORATE SOCIAL RESPONSIBILITY AND SUSTAINABILITY
}

\author{
Casiana IIle \\ Doctoral School of Economics, Faculty of Economics and Business, University of Oradea, \\ Romania \\ casiana.ille@gmail.com
}

\begin{abstract}
Corporate Social Responsibility (CSR) is still a developing domain both in study and practice surrounded by a lot of confusion as many authors have previously shown despite the considerable broad spectrum of approaches. Starting with the Ancient times and until nowadays, the notion has displayed sometimes chameleonic features and there are still discussions regarding a consensus on the topic. While the CSR concept can be traced back to Ancient times and contoured in the 1950's, the Corporate Sustainability (CS) concept can only be traced to the late 1980s when the concept of sustainable development (SD) was gaining momentum, as research conducted in the field has shown. Both CSR and corporate sustainability (CS) concepts have been in the spotlight in the last two decades and some researchers even use the terms interchangeably while others argue that the terms are different: similar, but not the same. Other authors dispute that each concept has a different origin that unravels a distinct pathway but they have both focalized on the same spot, using similar definitions, assumptions, same networks and measurement. More recent research suggests that CSR should be regarded and integrated as a component of CS strategy either as a transitional step or the final one for the business rather than keeping the two concepts on different pathways.

Even though the concepts are brought lately more together, the common theoretical aspects need more attention and a thorough discussion, some authors argue. Therefore, this research proposes a bibliometric analysis of the existing literature on CSR and CS during the past three decades since the globalisation of the terms. The approach of this study is comparative, seeking to picture the evolution of the global interest on the subject compared to the focus of the Romanian research regarding CSR and CS and SD.
\end{abstract}

Keywords: CSR; corporate sustainability; sustainable development.

JEL Classification: M14; L25.

\section{Introduction}

There is a growing interest globally towards Corporate Social Responsibility (CSR) especially since the issuance of the CSR and sustainability reports (the first reports were published in the 1980's by companies that were dealing with image difficulties - chemical and tobacco industry) where companies share annually with their stakeholders and communities the actions taken to integrate the principles of sustainable development and corporate responsibility in their day-to-day actions. These reports are important indicators regarding company's transparency, enabling them to analyse the impact of their agenda in order to improve the CSR approach and strategy. Moreover, the CSR and sustainability reports hold an important strategic potential because stakeholders (employees, customers, investors, media and other interested parties) can base their decisions on the goals the companies display in these reports and the public image "advertised" in the reports builds up the companies' portrait worldwide. 
The academic field has also increased the attention on the corporate social responsibility issue. This can be assessed by the impressive number of research articles published in the last decade in academic journals and magazines. A bibliometric analysis will be further presented in this paper.

CSR is still a developing domain both in study and practice surrounded by a lot of confusion (McWilliams and Siegel, 2011; Garriga and Mele, 2004) despite the considerable broad spectrum of approaches.

Starting with the Ancient times and until nowadays, the concept of CSR has displayed sometimes chameleonic features and there are still discussions regarding a consensus on the topic.

The present research consists of a literature review of the history and concept of corporate social responsibility and a bibliometric analysis regarding the number of publications on the topic. In the first part of the paper, a chronological and conceptual depiction of the evolution of the term was presented and the next section is focused on analysing different CSR paradigms, such as the business ethics approach and the stakeholder management theory.

\section{Milestones of the concept evolution in literature}

The concept of CSR can be traced back to ancient Roman times (Chaffee, 2017), when Roman senators introduced laws to foster safety for the poor and to ensure a basic state of equity. Evidence of rules and regulations that paved the way for the modern concept of CSR can be found in Christianity, referencing the Bible but it can be traced back also to Eastern cultures such as to King Hammurabi's Code around 1700 BC. As Vayanos points out in "The History of Corporate Social Responsibility" (2010), on every continent we would enquire, we would find early evidence of incipient stages of the CSR incentives that paved the way for building a concept in the modern years.

The early stages of socially responsible behavior consisted of rational resource usage, equity for the poor or responsible treatment of the wealthy towards the others, therefore mainly philanthropy and paternalism.

CSR was first defined as a concept the by Howard R. Bowen in 1953, setting the1950 - 1960 decade as the starting point - the early days of the modern era of social responsibility (Agudelo et al, 2019). Bowen (1953) sets a foundation for the development of the concept and introduces the idea that businesses must consider those politics that take into account the wellbeing of the society.

Building on that premises, the concept evolves in the 1970's from a managerial perspective, focusing on safety and labor rights (Preston and Post, 1975; Sethi, 1975; Carroll, 1979) and the corporate social responsibility literature is broadening, attracting with its expansion several critics. The most vocal critic is Milton Friedman (1970) who sustained the idea that the main purpose of the business is to create profit. As a response and in order to provide a solution to these critics, Carroll (1979) proposes a pyramidal approach that encompasses the main responsibilities but keeping the economic purpose at the base of the pyramid, incorporating the philanthropic one at the top. Carroll's construct was firstly depicted in 1979 and further developed as a pyramidal structure in 1991.

In the 1980's the concept of business ethics becomes an increasingly important part of the business vocabulary, making a new way for the operationalization on CSR (Jones, 1980; Tuzzolino and Armandi, 1981; Strand, 1983; Wood, 1984) due to the fact that corporations were given more power with governments reducing their role in regulating corporate behaviour (Agudelo et al., 2019). As a result, the business ethics concept begun to develop and terms as stakeholders became popular (Schwartz et al., 2008). This new facet broadened the CSR concept and scholars introduced complementary or alternative ideas 
such as corporate social performance, corporate social responsiveness or stakeholder theory (Carroll, 2008).

The globalization of the CSR inevitably took place in the next decade and the concept of "The Triple Bottom Line" was first introduced by Elkington in 1998, considering for the first time a new approach that adds into balance the companies' impact on society, environment and economy. This development was influenced by the creation of several international authorities that proposed regulations and set standards taking into account the issue of sustainable development. During this decade, the United Nations adopted the 21 Agenda and the Kyoto Protocol, the United Nations Framework Convention on Climate Change (UNFCCC) (1992) was signed and the European Environment Agency was created in 1990. These international events have indirectly set certain standards for corporations (Agudelo, et al, 2019). During this decade, the CSR concept started to draw more attention and important contributions are brought by Donna J. Wood (1991). Wood generated a unified theoretical concept building on the models of Carroll (1979) and Wartick and Cochran (1984). She formulated three dimensions to draw a model for Corporate Social Performance. Other important contributions during the 1990's come from Carroll's Pyramid (1991)

with the purpose to provide a balanced approach for the businesses in their social endeavors, keeping in mind their main purpose at the base of the pyramid-profit creation with the philanthropic responsibilities at the top (this approach will be discussed in a next section of this report). Going forward, Burke and Logsdon (1996) introduce the concept of strategic CSR with the purpose of creating a direct proportional relation between financial performance and CSR. They identify five dimensions of strategic CSR that will be further approached in this paper.

Starting with the year 2000 and the following decade, CSR receives even more recognition, expansion and implementation, building momentum for a strategic approach of the CSR provided by the academic publications (Smith, 2011; Lantos, 2001; Kramer, 2006; Marrewijk, 2003; Werther and Chandler, 2005; Husted and Allen, 2007). In the 2010's in the CSR discourse, the emphasis was placed on the creation of shared value (Porter and Kramer, 2011; Trapp, 2012; Chandler, 2016).

The concept of CSR has been studied from various perspectives since its appearance and a short history and the main milestones take us from the paternalism and philanthropic approach in the Ancient Times through many facets that lead to today's idea of sustainable development as presented in Figure 1. As discussed previously in this paper, the approaches are connected and mostly determined by the international climate and events and it is always tending to stabilize a concept that supports ethical, balanced sustainable value from different standing points.

Progressing on the trodden road of the CSR concept through all the stages that outline today's approach to CSR and sustainable development -yet incorporating all the milestones as important pieces of the puzzle- when faced with the global turbulent environment, deeper meanings can be associated. Therefore, nowadays especially in the context of the global pandemic, taking into consideration that risks are growing in times of economic uncertainty and that protecting existing contracts impose more risks (Coase, 1960) we can also detect a certain amount of new opportunities that arise on the other hand because social capital can be built through CSR incentives previous to the crisis period. These incentives will reduce the contracting costs due to existing trust and loyalty created through sustained longterm relationships with the external stakeholders (Chang et al, 2014). 


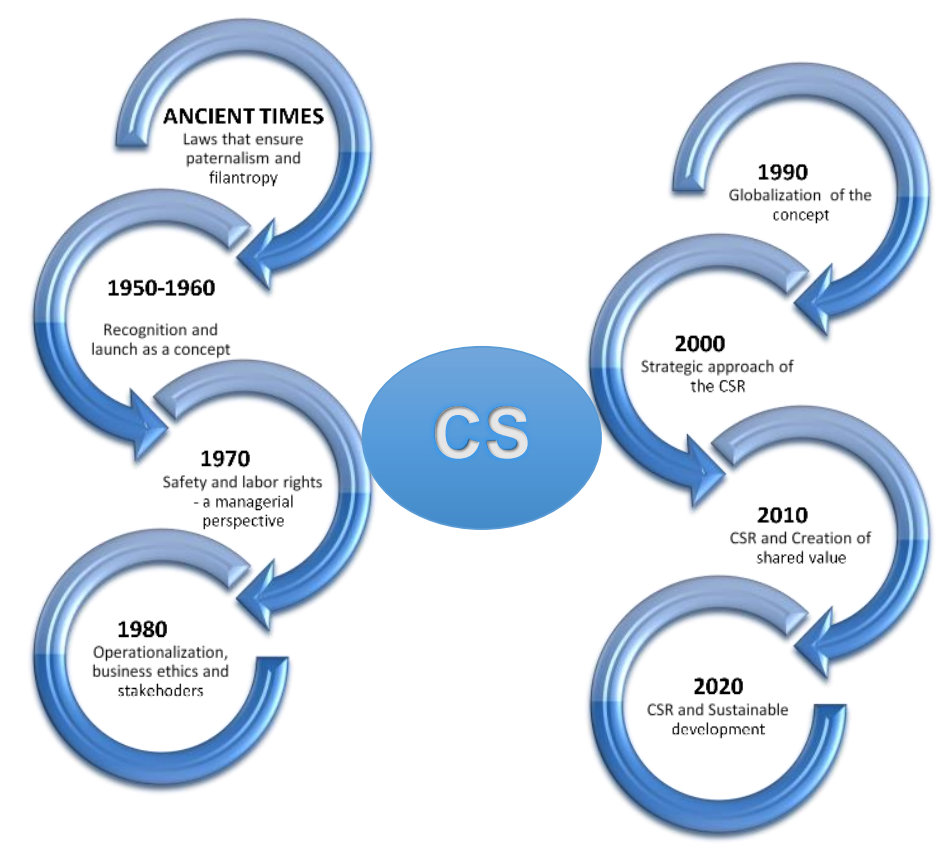

Figure 1: Milestones in the CSR concept development

Source: Author Representation after Agudelo et al., 2019

While the concept of CSR has been discussed and defined by numerous authors, one of the first authors to define it was Howard R. Bowen (1953) as "a commitment of entrepreneurs to seek strategies to make such decisions or carry out such activities which are desirable in terms of goals and values to our society" (Bowen, 1953, p 6, apud Carroll, 1999 p. 270). Taking into account a more recent definition given by Holme and Watts (2000), CSR is "the commitment of business to contribute to sustainable economic development, working with employees, their families, the local community and society at large to improve their quality of life". All things considered and each of the definitions we would cite here would deliver us the conclusion that CSR has decisive impact areas consisting of economy, society and the environment. As far as the economic area is concerned, businesses focus should be on improving the processes that pursue economic development and minimize the economic impacts and in regards to the societal point of view, they should be aiming on improving the quality of life (Radoslav, 2017).

There have been contradictory opinions in the literature regarding the role of business in society and Friedman (1970) argues that the only responsibility of the business is to create profit as long as it stays within the rules, referring to CSR as "a fundamentally subversive doctrine". However, practice evidence and research studies have proved that CSR activities benefit both the society and the company, adding value in times of economic growth but also adding substantially more value in times of uncertainty.

There is a lot of confusion and controversy around the CSR concept due to the wide and diverse approaches on one hand even if encompasses and builds itself on several theoretical established grounds such as stakeholder theory, business ethics, sustainable development and on the other hand also the common ground of these paradigms in itself can generate at times misunderstandings and criticism. 
Firstly, the concept developed naturally from ancient times and based its grounds in several other theoretical concepts such as business ethics, sustainable development, stakeholder theory, ethical consumerism and human rights through time. Developing an independent concept at the incidence of these theories should provide more light on the subject but actually it can create more controversy and generate critics because bringing more topics in the discussion can also create more confusion.

\section{Corporate Social Responsibility and Corporate Sustainability}

Both CSR and corporate sustainability (CS) concepts have been in the spotlight in the last two decades and some researchers even use the terms interchangeably (Montiel, 2014) while others argue that the terms are different: similar, but not the same (Bansal et al., 2017). Bansal and Song (2017) dispute that each concept has a different origin that unravels a distinct pathway but they have both focalized on the same spot, using similar definitions, assumptions, same networks and measurement. The authors recommendation for scholars is that rather than assuming that both constructs are the same, they should explore the differences, the complementarities and the integration of CSR and CS.

More recent research suggests that CSR should be regarded and integrated as a component of CS strategy either as a transitional step or the final one for the business rather than keeping the two concepts on different pathways (Ashrafi et al., 2018).

Even though the concepts are brought lately more together, the common theoretical aspects need more attention and a thorough discussion (Ashrafi et al., 2020).

While the concept of CSR can be traced back to Ancient times and contoured in the 1950's, the CS concept can only be traced to the late 1980s when the concept of sustainable development (SD) was gaining momentum (Schwartz et al., 2008).

Brundtland Commission Report defines sustainable development as "development that meets the needs of the present without compromising the ability of future generations to meet their own needs"(World Commission on Environment and Development- Our Common Future, 1987, p.41). This definition was seen as ambiguous and through time scholars tried to redefine SD and by 1992 there were more than 70 different definitions and the number increased to 300 by 2007 and researchers tried since 1990 to incorporate the SD concept and operationalize it to incorporate it into corporations, especially in regards with the environmental dimension (Ashrafi et al., 2020). Hart (1995) tried to underpin the benefits of incorporating environmental aspects into business. Other theoreticians tested several approaches to address and incorporate CS into businesses' decisions using resource based theory, the stakeholder's theory or the institutional theory (Ashrafi et al., 2020).

Through time, SD theory evolved and in 2000s a new and most cited definition was provided for SD by Dyllick and Hockerts (2002). These authors defined CS as "meeting the needs of a firm's direct and indirect stakeholders (such as shareholders, employees, clients, pressure groups, and communities), without compromising its ability to meet the needs of future stakeholders as well" (p. 131). The definition and conceptualization of CS is still evolving (Montiel, 2016).

Recent literature stresses the need for a clearer conceptualization of CS that would help businesses to shift to the new paradigm and incorporate it into its practices although theoreticians agree that there is no 'one-size-fits-all' business model that suits the idea of sustainability (Ashrafi et al., 2020). There has to be a conducted research that helps identify the proper factors that will help businesses harness sustainability through pragmatic solutions and initiatives (Landrum, 2017). In order to attain this purpose, there has to take place an investigation regarding the different levels of corporate sustainability sophistication that companies display in connection to their social, economic and environmental 
performance, together with balancing the stakeholder's partnerships that benefit the idea of sustainability (Amini, 2014).

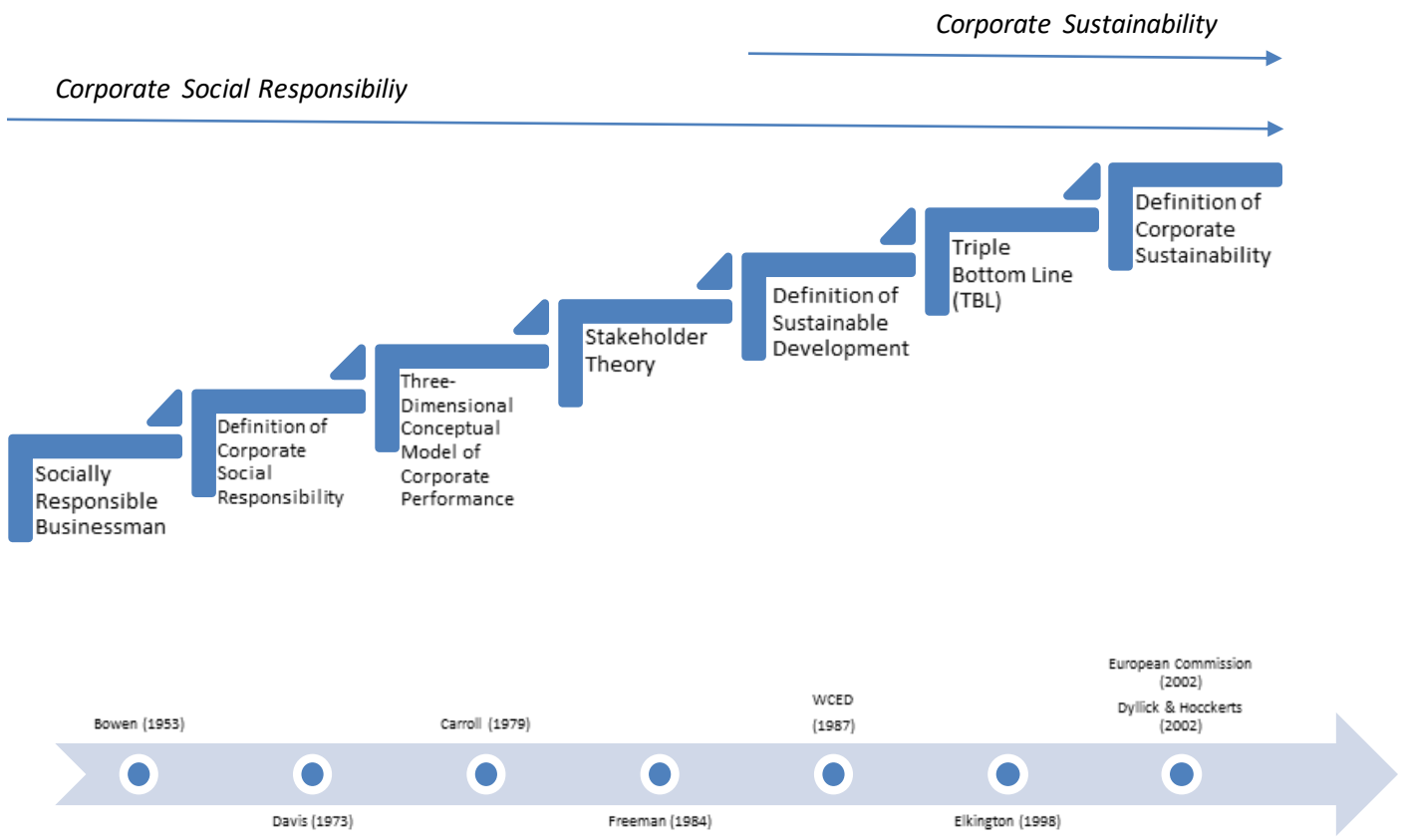

Figure 2: Chronology and theory development of corporate social responsibility and corporate sustainability

Source: Author's interpretation after Ashrafi et al., 2020

Figure 2 is a representation of the implications of the three theories that revolve around the sustainability and CSR concept: the institutional theory, the resource-based theory and the stakeholder theory. It can all be encompassed in an integrative theoretical framework as presented by Ashrafi et al. (2020), arguing that there is a dual force that drives the CSR and SD incentives: internal, referring to the resource-based theory and external, based on the institutional theory, in order to meet the interests of the multistakeholders (both internal and external), constructing on the stakeholder's theory. The authors go further and suggest that the three theories can be used in order to promote identification and operationalization of CSR and CS into the firm's strategy.

\section{A bibliometric analysis regarding the number of publications on the topic}

Corporate social responsibility has gained an increased attention during the last decades and the international pressure applied by stakeholders on the companies can be observed especially after numerous 'scandals' were reported regarding important firms such as banks, energy or telecom companies and others (Wagner 2006; Peters and Roess 2010; Mallen 2012). 
As a response, the academic field shifted interest on the study of CSR and the raise in the number of publications can be observed in Table 1 and Figure 3. Together with the raise in the number of research publications on the topic of CSR, also practitioners started to leverage their position and enhance stakeholder management. The evolutions can be observed by analyzing the actions of several organizations that have important influence worldwide that have been mentioned before in this study (OECD 2001; WBCSD 2002; UN Global Compact 1999; International Business Leaders Forum 2010a; International Organization for Standardization 2010, p. 4).

Table 1: Number of Publications on Corporate Social Responsibility

\begin{tabular}{|c|c|c|c|}
\hline Year & Web of Science & Science Direct & PRO Quest \\
\hline 2000 & 34 & 575 & 808 \\
\hline 2001 & 44 & 601 & 1132 \\
\hline 2002 & 51 & 617 & 1559 \\
\hline 2003 & 87 & 615 & 2154 \\
\hline 2004 & 126 & 682 & 2753 \\
\hline 2005 & 164 & 733 & 2956 \\
\hline 2006 & 201 & 893 & 3263 \\
\hline 2008 & 273 & 847 & 4429 \\
\hline 2009 & 430 & 939 & 4084 \\
\hline 2010 & 602 & 1031 & 5781 \\
\hline 2011 & 732 & 1109 & 7980 \\
\hline 2012 & 930 & 1454 & 8658 \\
\hline 2014 & 939 & 2012 & 11.749 \\
\hline 2015 & 1181 & 2023 & 11.974 \\
\hline 2016 & 1296 & 2834 & 16.520 \\
\hline 2017 & 2134 & 3335 & 16.663 \\
\hline
\end{tabular}

Source: Author's own work, data gathered from Web of Science, Science Direct and Pro Quest databases

Table 1 contains data gathered from Web of Science, Science Direct and Pro Quest databases for the number of publications in the last two decades. There was a spark in the international interest toward CSR starting with 1990, therefore in the first decade an ascending trend is expected and the interest was in this research to analyze the evolution after the first decade after the globalization of the term. The search in the databases was conducted using the term "corporate social responsibility". The numbers are resulted by using the following categories for each database:

For Science Direct, the numbers reflect the advanced search in the following categories:

- Review articles.

- Research articles.

- Case reports.

- Data articles.

- Editorials.

- Replication studies.

For Pro Quest database, the search was conducted for the articles in following categories:

- Source type: reports, conference papers and proceedings, working papers, standards and practice guidelines.

- Document type: all. 
- Language: all.

For Web of Science Database, the numbers reflect the advanced search in the themes and titles of the publications using the following categories:

- Language: all.

- Document type: articles; editorials; data study; case reports; data papers.

The numbers gathered in Table 1 can be artificially increased due to the fact that some of the publications could be encountered in more than one of the databases. Furthermore, regarding the qualitative perspective of this bibliometric analysis, it is relevant to mention that the Web of Science database usually gathers some of the most reputational and cited publications.

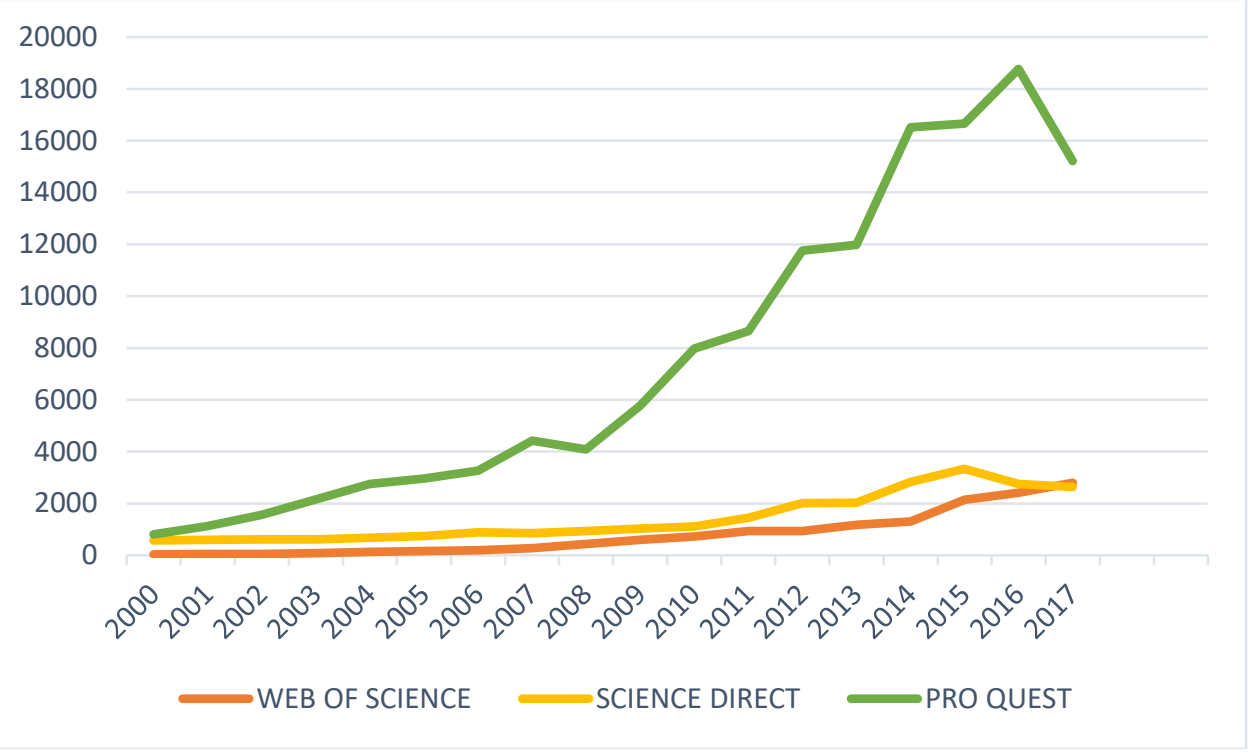

Figure 3: Evolution of the number of publications on "corporate social responsibility" Source: Author's development, data gathered from Web of Science, Science Direct and Pro Quest databases

Figure 3 pictures the time evolution of the number of publications containing the term "corporate social responsibility" for a better sight of the evolution. The findings bring us to the conclusion that there is a growing opportunity in terms of conceptualization and operationalization of the CSR especially because of the growing importance in the business field due to the strategic potential of shared value (Chandler, 2016). At the same time, in the scholarly literature the number of publications increased notably from 1109 in 2010 Science Direct to 3335 in 2015 and from 7980 in 2010 for Pro Quest to 16.663 in 2015 and 18.769 in 2016. It is interesting to observe that for the Pro Quest database, the number of publications had a slight drop in 2017 after being doubled in 2014 compared to 2011. The trend for Web of Science and for Science Direct publications on the topic of CSR are however following an ascending trend, underlining the idea that the topic is still in the spotlight and it gathers increased attention in the academic field.

Keeping the sight still at the ProQuest database numbers, the peak in 2016 with 2.35 times increase compared to 2010 can be attributed to the emphasis on the creation of shared value idea in the academic field, which sparked a special interest among researchers and practitioners. 
The increase in the number of publications shows that the concept remains relevant even if the contributions are not necessarily brought in the area of shaping the conceptual construct, but rather around its implementation and on specific areas of performance (Agudelo et al., 2019). Therefore, it cannot be only attributed to the new recommendations and regulations that shaped the international policy after 2010.

\section{A bibliometric analysis of the publications regarding CSR in Romania}

Considering the data that can be provided by analysing the big picture of the Romanian context, the research has been extended to country reports and academic publications regarding the education and CSR for education in Romania. Therefore, CSR has gained momentum in the 1990s when a great number of NGOs (non-profit organizations) were funded especially focused on humanitarian goals.

In the search of more data on the topic, it can be easily observed that nowadays, the concept in Romania still needs clarification because the meaning of CSR in somehow blurred and perceived by companies mostly just as philanthropic acts transposed from a concept introduced by corporations. Therefore, the case of Romanian companies involved in CSR is simply reduced to imitating foreign practices (Obrad, 2011). Despite the growing interest in the area, social responsibility programs and incentives are still at early stages of development (Baleanu et al., 2011) and CSR strategy is especially targeted at gaining reputational capital (Zait et al, 2015) without a consequent strategy and mostly circumstantial and subjective. The pathway for development and coordination to the European way is influenced by specific cultural factors and perceptions. In most of the cases CSR in Romania is still perceived as part of Marketing and PR and seen merely as philanthropy with an important inclination towards donations, sponsorships and public relations (Chersan, 2019). Although there are shy endeavours in the area of CSR in Romania, Popa (2015) highlighted that CSR activities in Romanian companies focus especially on areas relating to education, environment and community support.

Table 2: Number of Publications on Corporate Social Responsibility Concerning Romania

\begin{tabular}{|c|c|c|c|}
\hline Year & Web of Science & Science Direct & PRO Quest \\
\hline 2000 & 0 & 10 & 55 \\
\hline 2001 & 0 & 8 & 64 \\
\hline 2002 & 0 & 14 & 86 \\
\hline 2003 & 0 & 7 & 139 \\
\hline 2004 & 0 & 7 & 179 \\
\hline 2005 & 0 & 14 & 226 \\
\hline 2006 & 0 & 21 & 341 \\
\hline 2007 & 1 & 25 & 329 \\
\hline 2008 & 7 & 13 & 691 \\
\hline 2009 & 14 & 26 & 857 \\
\hline 2010 & 5 & 24 & 964 \\
\hline 2012 & 23 & 42 & 1190 \\
\hline 2013 & 9 & 117 & 1285 \\
\hline 2014 & 12 & 94 & 1715 \\
\hline 2015 & 27 & 216 & \\
\hline & 30 & & PRO Quest \\
\hline Year & & 85 & 1951 \\
\hline 2016 & Web of Science & Science Direct & 1506 \\
\hline
\end{tabular}


Source: Author's own work, data gathered from Web of Science, Science Direct and Pro Quest databases

In the international context where the number of publications concerning CSR grew exponentially in the last two decades and the presumption is that the same trends were followed in Romania, therefore the search was conducted precisely using the same indicator.

There was a spark also in the Romanian academic research interest toward CSR starting with 1990 when the concept became familiar to the domestic environment after the fall of the communism when corporations started to gain interest in the Romanian economy, bringing the new-then concepts of social responsibility and therefore in the first decade an ascending trend is expected and the interest was in this research to analyse the evolution after the first decade after the globalization of the term. The search in the databases was conducted using the term "corporate social responsibility" and "Romania". The numbers are resulted by using the previously mentioned categories for each database as in the search conducted for the international area.

The data contained in Table 2 is gathered from Web of Science, Science Direct and Pro Quest databases for the number of publications in the last two decades keeping the same parameters as in the search conducted for Table 1 but in the search the word "Romania" was added in order to refine the analysis for the publications concerning the country. The numbers can be artificially increased also in this search due to the fact that a number of publications may be in more than one of the researched databases. Romanian literature for CSR is as expected significantly lower compared to the international numbers but as it can be observed in Figure 4., they are following the same ascending trends.

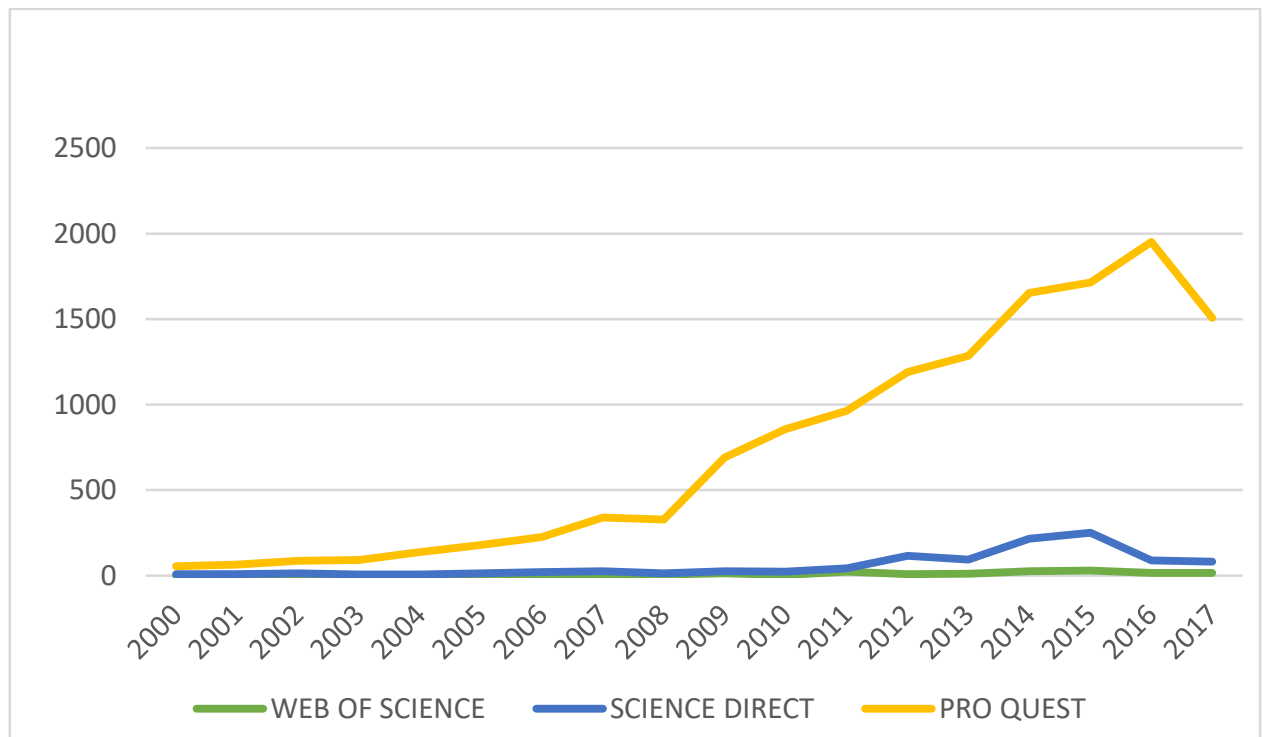

Figure 4: Evolution of the number of publications on "corporate social responsibility" concerning Romania

Source: Author's development, data gathered from Web of Science, Science Direct and Pro Quest databases

As depicted in Table 2, the publications for CSR regarding the Romanian context published on the Web of Science database started timidly with only one publication in 2007, reaching the peak in 2015 with 30 publications. The peak is however reached in 2015-2016 following 
the international trend even though at a lower level but the growth is exponential, displaying the flourishing raise in interest regarding the topic. This trend can be observed in Figure 4. Considering the data provided by this search, even if the numbers are not high, the peak still consists of the year 2016 and the growing rate is notable in the case of Romania, from 2000 to 2016. The growing interest can be attributed to the international trends but also to the growing number of corporations that relocated to Romania during these past years, bringing with them their corporate and CSR culture.

If we were to compare the peaks, there were 18.769 publications regarding CSR internationally and only 1951 Romanian studies on the topic in 2016, almost 10 times less. The difference is considerable and leads us to the conclusion that the subject is insufficiently researched in Romania.

\section{Conclusion}

As far as the concept of CSR is concerned, it was firstly defined as a concept the by Howard R. Bowen in 1953. The evolution of the concept was not smoothly agreed by theoreticians and several approaches were tested throughout the time and it drew several critics toward it, regarding the role of business in society and its objectives. After 1990, CSR drew a lot of attention in the academic and business field and the trend remained ascending even in the next two decades. Paradigms revolve around the business ethics theory, stakeholder management theory and sustainable development. These theories were analysed in the paper and a conceptualization of the often-confused terms "corporate social responsibility" and "corporate sustainability" was discussed. The two concepts are often used with the same meaning by some scholars and highly criticized as being two distinct concepts by others.

The rationale for engaging in CSR activities is argued by a vast literature regarding the empirical relationship of CSR and firm value and also by the fact that prosper societies provide the fertile ground for companies to develop.

The bibliometric analysis regarding the number of publications on CSR and CSR in Romania shows a similar ascendent trend in the last two decades worldwide and in Romania, with a peak in 2016 due to the intensive research regarding the strategic managerial approach during the period and also as a consequence of the new international regulations and treaties.

The findings gathered in this study lead to the conclusion that further research in the area of CSR is necessary and that especially studies for the Romanian context are needed due to the newness of the concept in the area and also due to the fact that the term is still under a lot of confusion.

\section{References}

1. Agudelo, M.A.L., Jóhannsdóttir, L. and Davídsdóttir, B. (2019) A literature review of the history and evolution of corporate social responsibility, International Journal of Corporate

Social Responsibility, 4(1). Available at: <https://link.springer.com/article/10.1186/s40991 -

018-0039-y> [Accessed 2 March 2020].

2. Amini, M.; Bienstock, C.C. (2014) Corporate sustainability: An integrative definition and framework to evaluate corporate practice and guide academic research, Journal of Cleaner

Production, 76, 12-19.

3. Ashrafi, M.; Adams, M.; Walker, T.R.; Magnan, G. (2018) How corporate social responsibility can be integrated into corporate sustainability: $A$ theoretical review of their relationships, The International Journal of Sustainable Development and World Ecology, 25, 672-682.

4. Ashrafi, M.; Magnan, G.M.; Adams, M.; Walker, T.R. (2020) Understanding the Conceptual Evolutionary Path and Theoretical Underpinnings of Corporate Social Responsibility and Corporate Sustainability, Sustainability, 12. 
5. Bansal, P.; Song, H.-C. (2017) Similar but not the same: Differentiating corporate sustainability from corporate responsibility, The Academy of Management Annals, 11, 105-

149.

6. Carroll, A.B. (1979) A three-dimensional conceptual model of corporate performance. Academy of Management Review, 4(4), pp.497-505.

7. Carroll. A.B. (1991) "The Pyramid of Corporate Social Responsibility: towards the Moral Management of organizational Stakeholders", Business Horizons, Vol.34, No.4, 39-48.

8. Carroll A. B. (1999) Corporate Social Responsibility: Evolution of a definitional construct, Business \& Society, 38. 268-295.

9. Chaffee, E.C., 2017. The Origins of Corporate Social Responsibility. [SSRN Scholarly Paper] Rochester, NY: Social Science Research Network. Available at: <https://papers.ssrn.com/abstract=2957820> [Accessed 17 Apr. 2020].

10. Chandler, D. (2016). Strategic corporate social responsibility: sustainable value creation. Thousand Oaks: SAGE Publications.

11. Chersan, I.C. and Danilet M. (2019) A content analysis of transparency reports of big four in Europe. In M. Tofan, I. Bilan and E. Cigu (eds). European Union Financial Regulation

and Administrative Area, EUFIRE 2019. Iaşi, Romania. Editura Universităţii "Alexandru Ioan Cuza" din laşi, pp.393-404.

12. Cochran, P.L. and Wood, R.A. (1984) Corporate social responsibility and financial performance. The Academy of Management Journal, 27(1), pp.42-56.

13. Dyllick, T.; Hockerts, K. (2002) Beyond the business case for corporate sustainability, Business Strategy and the Environment, 11, 130-141.

14. Elkington, J. (1998) Partnerships from cannibals with forks: The triple bottom line of 21st-century business. Environmental Quality Management, 8(1), pp.37-51.

15. Friedman, M. (1970). The social responsibility of business is to increase its profits, New York Magazine, September issue.

16. Garriga, E.; Melé, D. (2004) Corporate social responsibility theories: Mapping the territory. Journal of Business Ethics, 53(1-2), pp.51-71.

17. Hart, S.L. (1995) A natural-resource-based view of the firm, Academy of Management

Review, 20, 986-1014.

18. Holme, R. and Watts, P. (2000) Corporate social responsibility: making good business

sense. Geneva: World Business Council for Sustainable Development.

19. Landrum, N.E. (2017) Stages of corporate sustainability: Integrating the strong sustainability worldview. Organization and Environment, 31, 287-313.

20. Lantos, G. P. (2001). The boundaries of strategic corporate social responsibility. Journal of Consumer Marketing, 18(7), 595-632.

21. McWilliams, A. and Siegel, D.S. (2011) Creating and capturing value: Strategic corporate social responsibility, resource-based theory, and sustainable competitive advantage. Journal of Management, 37(5), pp.1480-1495.

22. Montiel, I.; Delgado-Ceballos, J. (2014) Defining and measuring corporate sustainability: Are we there yet?, Organization \& Environment, 27, 113-139.

23. Obrad, C., Petcu, D., Gherheş, V. and Suciu, S. (2011) Corporate social responsibility in Romanian companies-between perceptions and reality. Amfiteatru Economic Journal, 13(29), pp.4355.

24. Popa, R.A. (2015) The Corporate Social Responsibility Practices in the Context of Sustainable Development. The Case of Romania. Procedia Economics and Finance, 23, pp.1279-1285.

25. Porter, M. E., \& Kramer, M. R. (2006). Strategy \& Society. Harvard Business Review, December, $1-16$.

26. Porter, M. E., \& Kramer, M. R. (2011). Creating shared value. Harvard Business Review

(January-February).

27. Schwartz, M.S.; Carroll, A.B. (2008) Integrating and unifying competing and complementary frameworks: The search for a common core in the business and society field, Business \& Society, 47 , 148-186.

28. Sethi, S. P. (1975). Dimensions of corporate social performance: An analytical framework. California Management Review, 17(3), 58-64.

29. Smith, P., \& Sharicz, C. (2011) The shift needed for sustainability. The Learning Organization, 18(1), 73-86. 
The Annals of the University of Oradea. Economic Sciences

TOM XXX, $1^{\text {st }}$ Issue, July 2021

30. Tuzzolino, F., \& Armandi, B. R. (1981) A need-hierarchy framework for assessing corporate social responsibility. The Academy of Management Review, 6(1), 21-28.

31. Werther, W. B.; Chandler, D. (2005). Strategic corporate social responsibility as global brand insurance. Business Horizons, 48(4), 317-324.

32. World Commission on Environment and Development (1987) Our Common Future, Oxford University Press, p. 27. ISBN 019282080X. 